16,05

\title{
О магнетизме кластеров никеля в нанопористом углероде
}

\author{
(C) А.М. Данишевский ${ }^{1}$, Б.Д. Шанина ${ }^{2}$, А.Ю. Рогачев ${ }^{1}$, В.В. Соколов ${ }^{1}$, \\ A.Е. Калмыков ${ }^{1}$, Р.Н. Кютт ${ }^{1}$, С.К. Гордеев ${ }^{3}$ \\ ${ }^{1}$ Физико-технический институт им. А.Ф. Иоффе РАН \\ Санкт-Петербург, Россия \\ ${ }^{2}$ Институт полупроводников, \\ Киев, Украина \\ ${ }^{3}$ Центральный научно-исследовательский институт материалов, \\ Санкт-Петербург, Россия \\ E-mail: Alex.D@mail.ioffe.ru
}

(Поступила в Редакцию 22 марта 2017 г.)

\begin{abstract}
Исследованы структурные и магнитометрические характеристики образцов нанопористого углерода с кластерами никеля в нанопорах. Основное внимание обращено на факт существенного уменьшения намагниченности никеля, имеющего тесный контакт с углеродом, в сравнении с аналогичным параметром свободных никелевых микрочастиц примерно тех же размеров. Построена теоретическая модель периодического кластера, состоящего из 16 атомов углерода и одного атома никеля в нанопоре, окруженного углеродными атомами. Выполнены компъютерные расчеты электронных плотностей в таком кластере и его магнетизма. Показано, что магнитный момент никелевого атома в кластере существенно меньше, чем для свободного атома никеля. Исходя из указанных результатов, был сделан вывод, что наблюдаемый в эксперименте эффект уменьшения намагниченности никелевых кластеров в углеродном окружении связан с адсорбционным взаимодействием электронных подсистем никеля и углерода.
\end{abstract}

DOI: 10.21883/FTT.2017.10.44980.085

\section{1. Введение}

Экспериментальное изучение магнитных свойств очень малых никелевых частиц в матрицах различно приготовленных углеродных систем проводится уже на протяжение ряда лет (см., например, работы [1-6]). В некоторых из них $[1,2,4,6]$ на основе сравнения с магнитными свойствами свободных никелевых частиц отмечается существенное уменьшение намагниченности насыщения в случае, когда эти частицы находятся в углеродной матрице. Следует, однако, заметить, что многообразие способов синтеза, каждый из которых вносит свои особенности в структуру получаемых композитов, усложняет анализ результатов. В [2], в частности, наноразмерные Ni кластеры в углероде создавались при дуговом разряде $(30 \AA)$ между графитовым и никельграфитовым электродами, помещенных в деионизованную воду, и это позволяло получить $\mathrm{Ni}$ частицы, окруженные углеродной структурой, с различными размерами при относительно узком размерном распределении. Авторы приводят значения намагниченности насыщения $\left(I_{s}\right)(300 \mathrm{~K})$ никелевых частиц в углеродной матрице 7.2, 14 и $38.6 \mathrm{emu} / \mathrm{g}$ соответственно для трех размеров $\mathrm{Ni}$ частиц 14, 24 и $30 \mathrm{~nm}$, и они сопоставляются с аналогичными величинами $I_{s}$ для чисто $\mathrm{Ni}$ частиц 37.7 и $49.3 \mathrm{emu} / \mathrm{g}$ с размерами 21.6 и $48.8 \mathrm{~nm}$ соответственно. Указанный параметр $\left(I_{s}\right)$ для массивного ферромагнитного никеля составляет $55.1 \mathrm{emu} / \mathrm{g}(300 \mathrm{~K})$ [7]. Авторы [2] указывают, что капсуляция $\mathrm{Ni}$ частиц в графит приводит к тем более сильному уменьшению намагниченности, чем меньшим является размер частиц из-за более высокого отношения их суммарной поверхности к объему в такой системе. Тем не менее, они не предлагают какого-либо конкретного механизма для объяснения указанного воздействия на магнитную подсистему.

В работе [6] для получения наночастиц никеля, покрытых углеродной оболочкой, использовалась оригинальная газофазная установка, позволяющая проводить плавку металла во взвешенном состоянии с помощью индукционного нагрева, испарения расплавленного металла и конденсации паров металла в потоке инертного газа $\mathrm{Ar}$, содержащего углеводород бутан. Исследовалась структура и магнитные свойства полученных композитов. В работе [6] использовались методы мессбауэровской спектроскопии, просвечивающей электронной микроскопии высокого разрешения и рентгенофазового анализа. Были получены образцы с размерами кластеров $\mathrm{Ni} 5 \mathrm{~nm}$ в углеродной оболочке (содержание угдерода $39 \mathrm{wt} . \%$ ) и $15 \mathrm{~nm}$ (содержание углерода 21 wt.\%). Намагниченность насыщения $\mathrm{Ni@C}$ не достигает величины, рассчитанной в двухфазной модели (металлическое ядро + углеродная оболочка). Так, для образца Ni@C-5 nm следует ожидать величину удельной намагниченности насыщения, равную $33 \mathrm{emu} / \mathrm{g}$. Однако в поле $15 \mathrm{~T}$ при $77 \mathrm{~K}$ эта величина составляет примерно $27 \mathrm{emu} / \mathrm{g}$; такое же расхождение наблюдается для образца $\mathrm{Ni} @ \mathrm{C}-15 \mathrm{~nm}$ - вместо рассчитанной величины $43 \mathrm{emu} / \mathrm{g}$ (с учетом углеродного покрытия) измеренная величина $I_{s}$ составляет $33 \mathrm{emu} / \mathrm{g}$.

Авторы объясняют указанное несоответствие образованием вблизи границы металла и углерода твердого раствора $\mathrm{Ni}(\mathrm{C})$. Они предполагают, что, несмотря на 

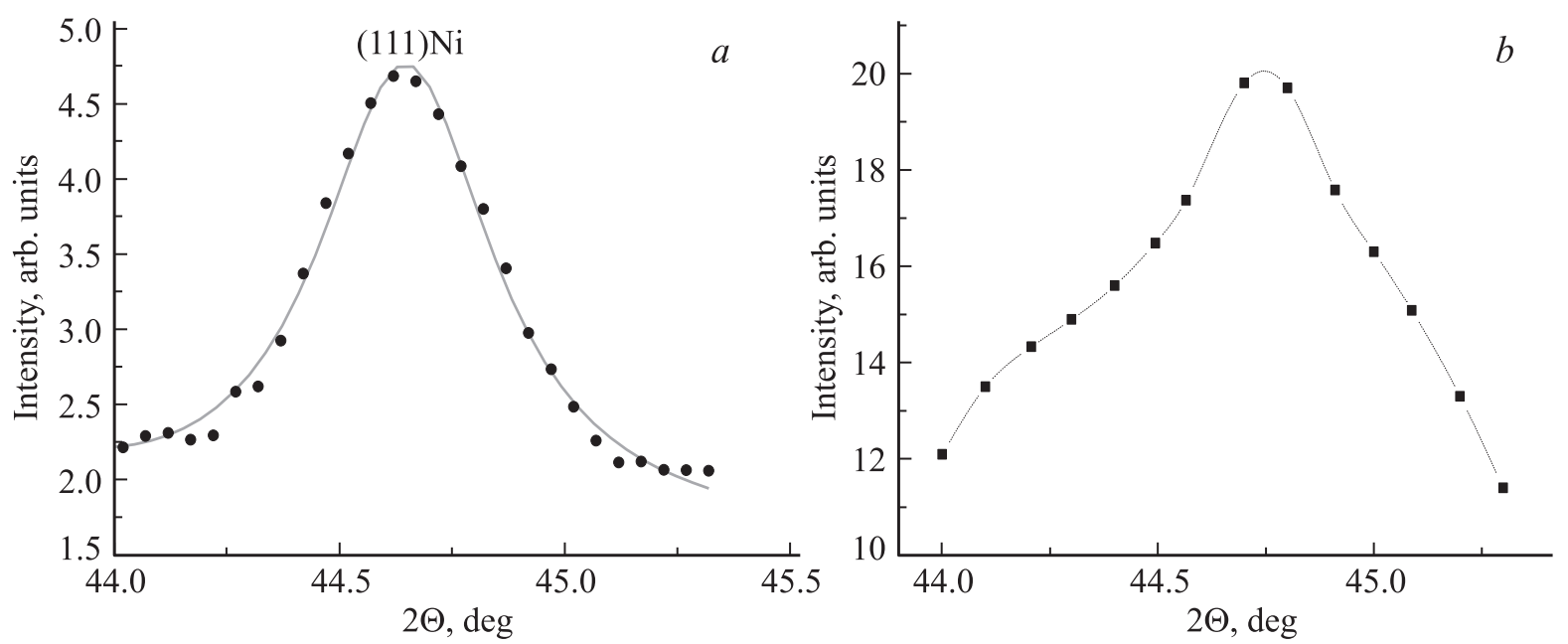

Рис. 1. Контуры рентгеновской дифракции никелевых кластеров в порошках КНПУ: $a-\mathrm{C}(\mathrm{SiC}): \mathrm{Ni}, b-\mathrm{C}\left(\mathrm{B}_{4} \mathrm{C}\right): \mathrm{Ni}$.

отсутствие заметной растворимости углерода в массивном Ni на равновесной фазовой диаграмме в системе $\mathrm{Ni}-\mathrm{C}$ (максимальная растворимость углерода в никеле не превышает 2.7 at.\% [8]), в нанодиапазоне, тем не менее, формируется твердый раствор $\mathrm{Ni}(\mathrm{C})$ с широкой областью гомогенности.

Следует сказать, что указанные в упомянутых работах системы $\mathrm{Ni}-\mathrm{C}$ были получены при достаточно высоких температурах, что, в принципе, благоприятствует диффузии и образованию твердого раствора вблизи границы раздела.

В настоящей работе исследуются магнитные свойства никель-углеродных систем с относительно небольшим содержанием кластеров никеля, полученных при значительно более низких температурах. Также приведены результаты расчетов электронных и магнитных свойств модельных периодических никель-углеродных кластеров, состоящих из 16 атомов углерода и одного атома $\mathrm{Ni}$ в нанопоре, окруженного атомами углерода.

\section{2. Исследуемые образцы}

Кластеры никеля создавались в пористой матрице углерода. В качестве такой объемной матрицы использовался нанопористый углерод, приготовленный из карбидов (КНПУ или CDC in USA) путем химического удаления карбидообразующих элементов в атмосфере хлора. Образцы КНПУ обладают высокой пористостью и имеют однородные по размеру микропоры, несколько отличающиеся по размерам в зависимости от типа исходного карбида [9].

В данной работе изучались порошкообразные образцы $\mathrm{C}\left(\mathrm{B}_{4} \mathrm{C}\right), \mathrm{C}(\mathrm{SiC})$ с введенными в них кластерами никеля. Размер зерен порошка $\mathrm{C}(\mathrm{SiC})$ был около $63 \mu \mathrm{m}$, a размер микропор в порошинках, определенный из кривых адсорбции азота - $\sim 0.8 \mathrm{~nm}$, полная пористость - 52\%, нанопористость - 50\%, удельная поверхность $1440 \mathrm{~m}^{2} / \mathrm{g}$. В порошке $\mathrm{C}\left(\mathrm{B}_{4} \mathrm{C}\right)$ размер зерна был $\sim 5 \mu \mathrm{m}$, полная пористость $-73.5 \%$, нанопорстость - 71.5\%, удельная поверхность $1180 \mathrm{~m}^{2} / \mathrm{g}$, размер микропор - 0.9-2 nm. Для введения никеля указанные образцы КНПУ в течение $\sim 0.5$ часа кипятились в водном растворе нитрата никеля $(0.1 \mathrm{M})$, далее в раствор добавлялось небольшое количество сахарозы, и кипение продолжалось еще 20-25 минут, после чего раствор фильтровался и полученный осадок просушивался. Далее с целью восстановления металлического никеля в порах углерода образцы отжигались в проточном водороде при температуре $410-420^{\circ} \mathrm{C}$ в течение 4 часов, а затем еще час при этой же температуре для удаления водорода продувались газообразным аргоном и также в потоке аргона охлаждались до комнатной температуры. Сахароза при указанных температурах трансформируется в наноуглерод, который может осадиться на $\mathrm{Ni}$, замедляя окисление образовавшихся в процессе отжига кластеров металлического никеля.

Полученные порошки КНПУ : Ni исследовались рентгеновскими методами, на электронном просвечивающем микроскопе и магнетометре.

\section{3. Рентгеновские исследования}

В картинах рентгеновской дифракции образцов КНПУ [10] наблюдались два существенно уширенных пика в интервале углов $2 \Theta=23.5-27^{\circ}$ и $42-46^{\circ}$. При введении Ni в изучаемые образцы в дифракционных картинах появляются добавочные пики, относящиеся к никелевым кристаллитам. Наиболее интенсивный пик рентгеновского отражения 111 никеля в образце $\mathrm{C}(\mathrm{SiC}): \mathrm{Ni}$ представлен на рис. 1,a. Средний размер никелевых фрагментов, определнный из угловой ширины дифракционного пика в соответствии с формулой Шерера равен $18 \mathrm{~nm}$. Для образца $\mathrm{C}\left(\mathrm{B}_{4} \mathrm{C}\right): \mathrm{Ni}$ аналогичный пик показан на рис. $1, b$. Размер кластеров $\mathrm{Ni}$ примерно $12 \mathrm{~nm}$. 

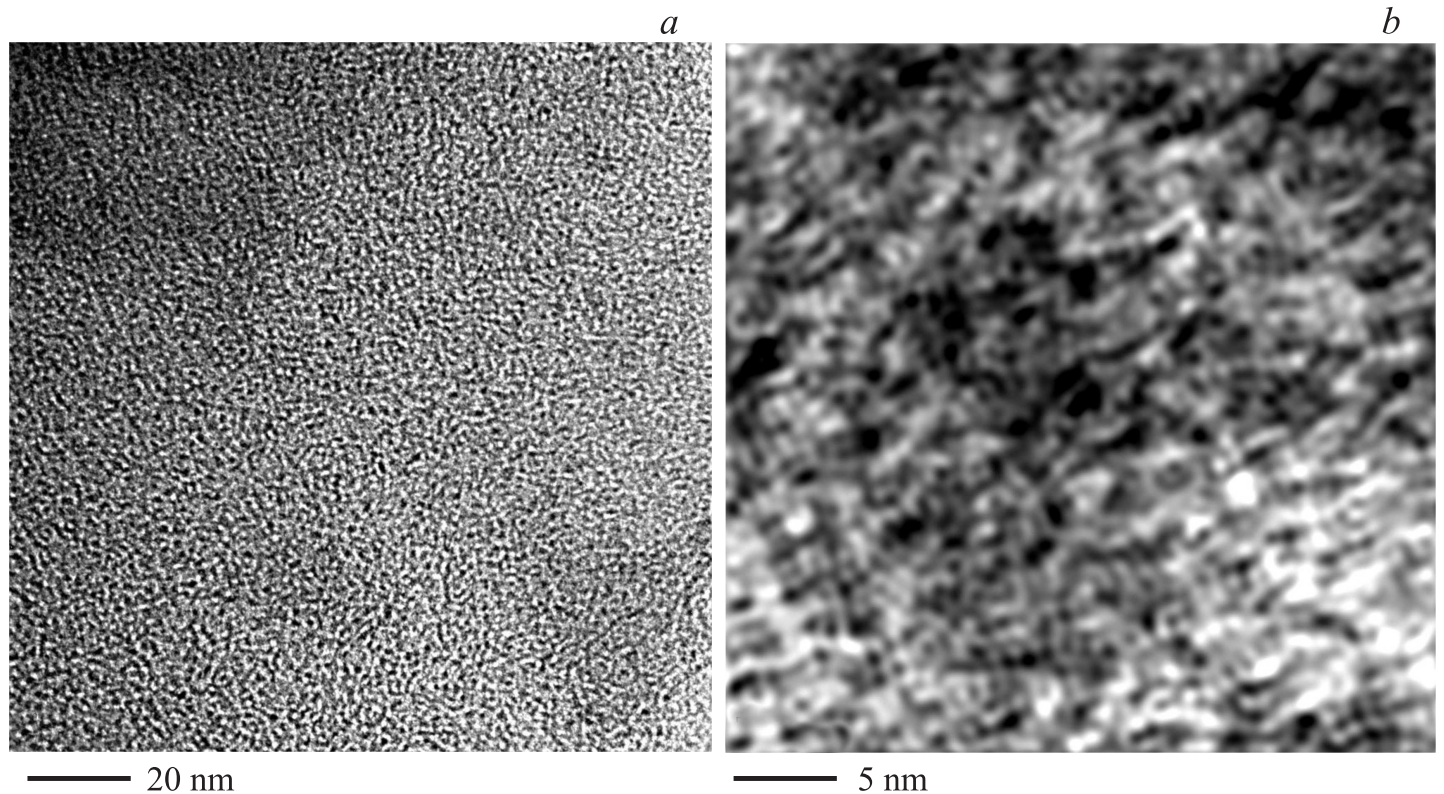

Рис. 2. Структуры порошков КНПУ $\mathrm{C}(\mathrm{SiC})-(a)$ и $\mathrm{C}\left(\mathrm{B}_{4} \mathrm{C}\right)-(b)$, полученные в ПЭМ высокого разрешения (ПЭМ ВР) и гистограммы размеров $\mathrm{Ni}$ кластеров.

Помимо дифракционных картин, изучалось поглощение рентгеновского луча в образцах указанных выше порошков. Поскольку масса атома $\mathrm{Ni}$ (и значение параметра $Z$ ) значительно больше, чем для углеродного атома, поглощение рентгеновского луча в основном определяется никелевыми атомами, что дает возможность из данных по коэффициенту поглощения определить концентрацию атомов никеля $N_{\mathrm{Ni}}$. Для порошка $\mathrm{C}(\mathrm{SiC}): \mathrm{Ni}$ концентрация $N_{\mathrm{Ni}}$ оказалась $N_{\mathrm{Ni}}=1.62 \cdot 10^{21} \mathrm{~cm}^{-3}$, для $\mathrm{C}\left(\mathrm{B}_{4} \mathrm{C}\right): \mathrm{Ni} N_{\mathrm{Ni}}=8.37 \cdot 10^{20} \mathrm{~cm}^{-3}$.

\section{4. Электронно-микроскопические исследования}

Структура образцов изучалась также электронномикроскопическими методами (ПЭМ). На рис. 2 приведены структуры порошков КНПУ $\mathrm{C}(\mathrm{SiC})-(a)$ и $\mathrm{C}\left(\mathrm{B}_{4} \mathrm{C}\right)-(b)$, полученные в ПЭМ высокого разрешения (ПЭМ ВР). Оценка толщин углеродных мостиков между порами показывает, что для $\mathrm{C}(\mathrm{SiC})$ это величины порядка $1.2-1.5 \mathrm{~nm}$, а для $\mathrm{C}\left(\mathrm{B}_{4} \mathrm{C}\right)$ меньше $1 \mathrm{~nm}$.

На рис. 3, $а$ приведена структура образца $\mathrm{C}(\mathrm{SiC}): \mathrm{Ni}$, a на рис. $3, b$ образца $\mathrm{C}\left(\mathrm{B}_{4} \mathrm{C}\right)$. Хотя средние размеры микропор, полученные из результатов адсорбционных и рентгеновских (малоугловое рентгеновское рассеяние) измерений, равны $0.8 \mathrm{~nm}$, на приведенных рисунках видны гораздо более крупные образования металла с размерами 5-20 nm. То, что указанные частицы образованы именно никелем с ГЦК структурой, подтверждается картиной электронной дифракции. Такой эффект возможен благодаря тому, что микропоры соединяются друг с другом и металл, формируя при отжиге в водороде кластер, охватывает большое количество рядом расположенных микропор. В этом случае внутри металлического кластера должны оставаться элементы углеродного каркаса. Однако на снимках, полученных в ПЭМ, какая-то внутренняя структура кластера просматривается. только на некоторых изображениях металлических частиц. Альтернативный вариант объяснения роста относительно больших по объему никелевых кластеров в углеродной матрице связан с тем, что в процессе водородного отжига (проводимого для восстановления металлического Ni) благодаря катализируемому металлом процессу возникает „испарение“ углеродных стенок пор за счет химической реакции образования летучих углеводородов. Последнее предположение подтверждается и тем, что при водородном отжиге $\left(T=410-420^{\circ} \mathrm{C}\right.$, 4 h.) исходных порошков КНПУ в отсутствие металлакатализатора, их масса также уменьшается на 6-10\%. Возможно, оба указанных процесса роста металлических кластеров в КНПУ сосуществуют.

На рис. 3, $b$ показана микроскопическая структура фрагмента порошка $\mathrm{C}\left(\mathrm{B}_{4} \mathrm{C}\right): \mathrm{Ni}$. Здесь также размеры металлических кластеров распределены в диапазоне $5-20 \mathrm{~nm}$.

\section{5. Магнитные характеристики КНПУ : Ni}

Доменная структура массивного ферромагнетика, как известно, возникает в результате минимизации суммарной энергии, в которую входят: обменная энергия, энергия кристаллографической анизотропии, а также магнитостатическая и магнитострикционная энергии. Еще в работе [11] было предсказано, что достаточно малые частицы ферромагнетика должны становиться однодоменными, поскольку при уменьшении диаметра 

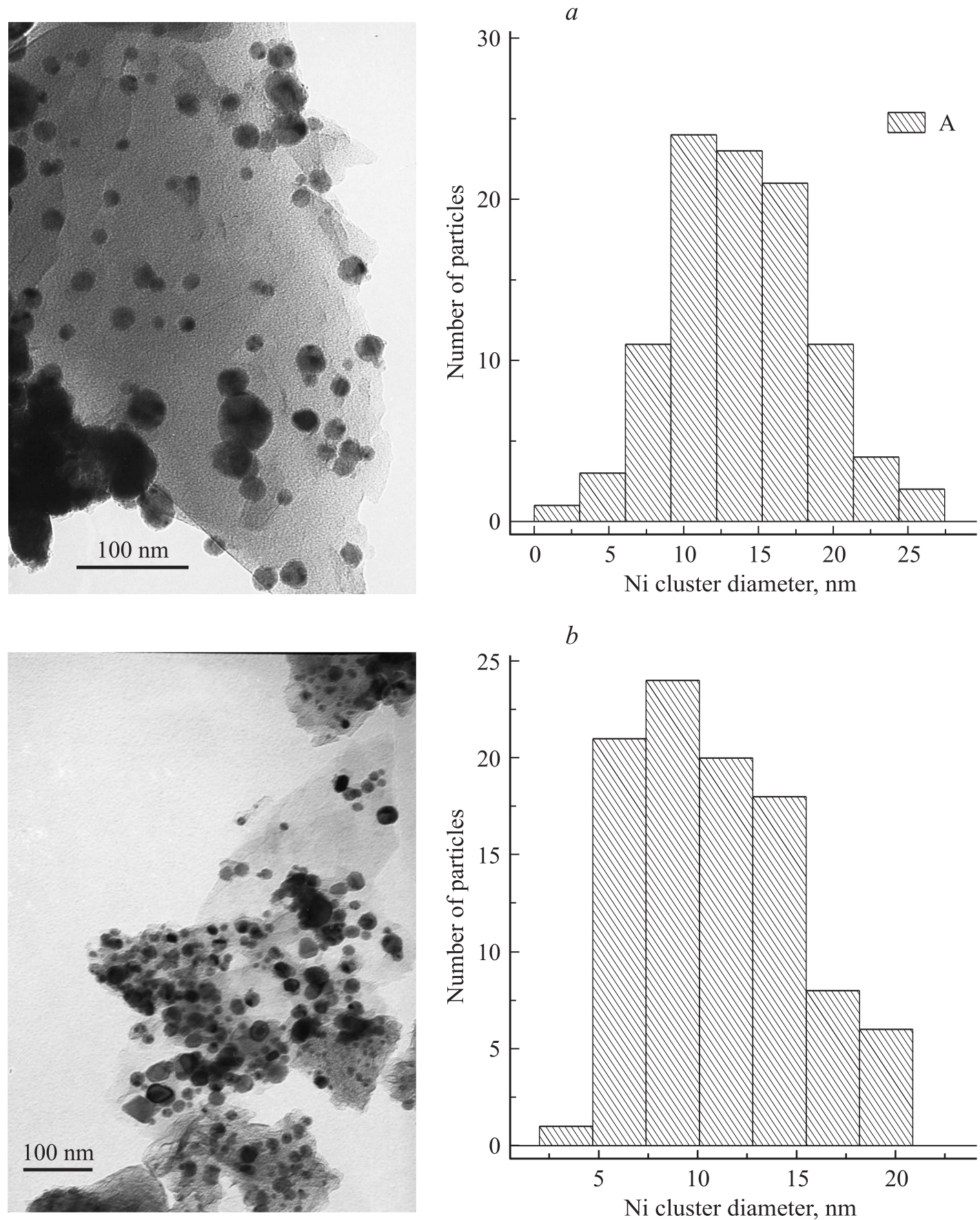

Рис. 3. Изображения никелевых кластеров (ПЭМ) в образцах: $a) \mathrm{C}(\mathrm{SiC}): \mathrm{Ni}, b) \mathrm{C}\left(\mathrm{B}_{4} \mathrm{C}\right): \mathrm{Ni}$.

частицы магнитостатическая энергия, пропорциональная объему, убывает быстрее, чем энергия границы между доменами, пропорциональная поверхности. Для никеля значение критического диаметра сферических частиц, при котором сохраняется однодоменность приведено в работе [12], и оно равно $55 \mathrm{~nm}$.

В существенно меньших частицах магнитная подсистема ведет себя подобно ансамблю парамагнитных атомов, что соответствует суперпарамагнитному состоянию. В этом случае как остаточная намагниченность $I_{R}$, так и коэрцитивная сила $H_{c}$ стремятся к 0 . В работе [13] приведены экспериментальные зависимости $I_{R}$ и $H_{c}$ от диаметра свободных частиц $\mathrm{Ni}$, откуда видно, что в суперпарамагнитное состояние частицы $\mathrm{Ni}$ переходят при диаметре $d<20 \mathrm{~nm}$.

Магнитные характеристики образцов КНПУ : Ni измерялись на лабораторном вибрационном магнетометре, отградуированном по образцу из малых кусочков чистой никелевой проволоки в соответствии с данными по $I_{s}$, полученными в работе [7].

На рис. 4 приведены кривые намагниченности от поля, измеренные для образца порошка $\mathrm{C}\left(\mathrm{B}_{4} \mathrm{C}\right)$ : $\mathrm{Ni}$ в различ- 


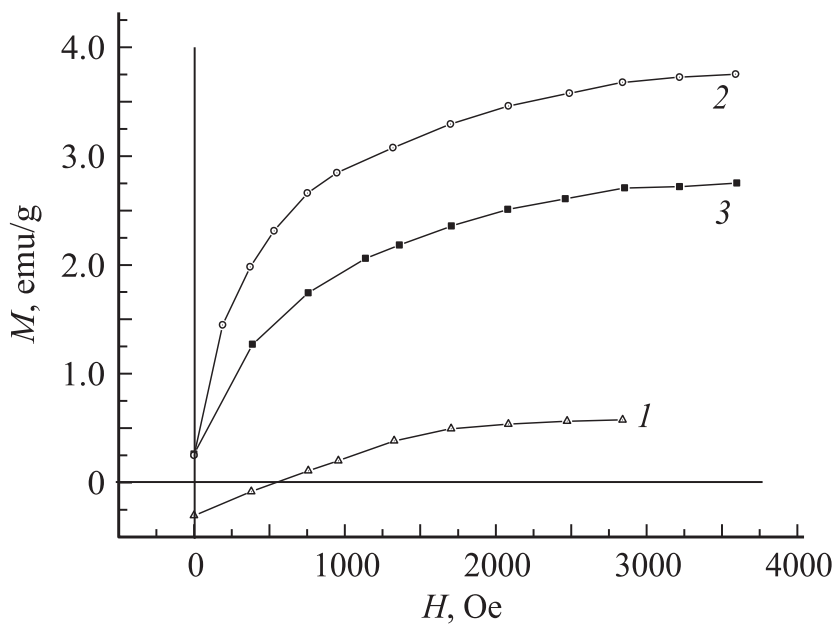

Рис. 4. Зависимости намагниченности от поля, измеренные для образца $\mathrm{C}\left(\mathrm{B}_{4} \mathrm{C}\right): \mathrm{Ni}$ в различные промежутки времени: 1 - через $15 \mathrm{~h}$ после водородного отжига, 2 - через 1 неделю после отжига, 3 - через 2 недели после отжига.

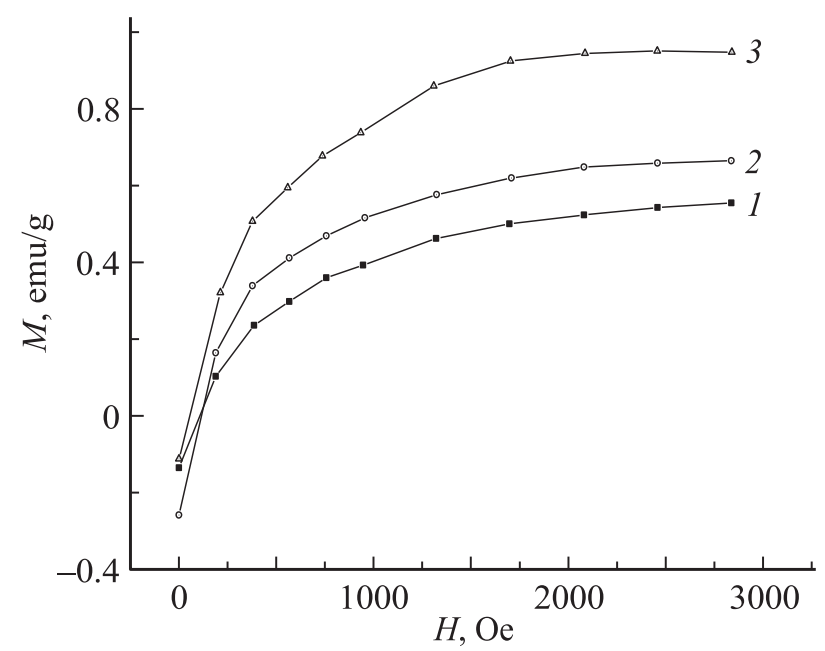

Рис. 5. Зависимости намагниченности от поля, измеренные для образца $\mathrm{C}(\mathrm{SiC}): \mathrm{Ni}$ в различные промежутки времени: 1 - через $15 \mathrm{~h}$ водородного отжига, 2 - через 23 суток после отжига, 3 - через 70 суток после отжига.

ные сроки после восстановления металлического $\mathrm{Ni}$ в процессе водородного отжига. Из данных зависимостей видно влияние адсорбции на намагниченность. В приведенном случае - влияние водородной адсорбции. Несмотря на окончательный отжиг в атмосфере аргона, водород, по-видимому, не уходит полностью. В работе [12] показано, что при диссоциативной адсорбции водорода на никеле, два атома никеля на одну адсорбированную молекулу водорода из магнитного взаимодействия исключается.

Кривые намагниченности от поля, построенные на рис. 4 для образца $\mathrm{C}\left(\mathrm{B}_{4} \mathrm{C}\right): \mathrm{Ni}$, получены через $15 \mathrm{~h}(1)$ после водородного отжига, через 1 неделю (2) и через 2 недели (3) после отжига. За первую неделю намагниченность насыщения увеличивается в $\sim 6.5$ раз и доходит до значения $\sim 3.75 \mathrm{emu} / \mathrm{g}$. Столь большой промежуток времени, возможно, обусловлен наличием хемосорбции водорода на никеле. По прошествии двух недель (кривая 3) намагниченность несколько падает, и это, видимо, связано с поверхностным окислением $\mathrm{Ni}$ кластеров в углеродной матрице $\mathrm{C}\left(\mathrm{B}_{4} \mathrm{C}\right)$.

Для образца $\mathrm{C}(\mathrm{SiC}): \mathrm{Ni}$ (рис. 5) измерения, проведенные через $15 \mathrm{~h}$ и через 23 дня после отжига, дали качественно аналогичные результаты.

Намагниченность насыщения через $15 \mathrm{~h}$ оказалась равной $\sim 0.54 \mathrm{emu} / \mathrm{g}$, по происшествии 23 суток $0.67 \mathrm{emu} / \mathrm{g}$, но через 70 суток она возросла до $0.88 \mathrm{emu} / \mathrm{g}$; последняя цифра, правда, была получена из аппроксимации экспериментальной зависимости намагниченности от поля функцией $A_{1} \cdot L(H)+A_{2} \cdot H$, где $L(H)-$ функция Ланжевена, и последующим вычитании линейного члена $\left(A_{2}=7.1 \cdot 10^{-4}\right)$ из экспериментальной кривой. Появление указанного линейного вклада в намагниченность, по-видимому, связано с достаточно заметным влиянием антиферромагнитной компоненты при образовании NiO.

Таким образом, не трудно видеть, что полученные значения намагниченности насыщения для обоих образцов углерода с никелевыми кластерами существенно меньше аналогичных значений для свободных частиц никеля близких размеров, приведенных выше.

Следует, однако, заметить, что приведенные значения (в единицах emu/g) были получены, исходя из массы измеряемого композита, а не массы никеля, содержащегося в нем.

Как указывалось выше, из данных поглощения потока рентгеновского излучения в данных образцах была определена концентрация атомов никеля, и это дало возможность оценки процентного содержания никеля по удельной средней плотности $\left(\rho_{\mathrm{Ni}}\right)$ в составе композита. Так для $\mathrm{C}(\mathrm{SiC}): \mathrm{Ni}$ отношение $\left(\rho_{\mathrm{Ni}} / \rho_{\mathrm{C}}\right)=0.158$, а для образца $\mathrm{C}\left(\mathrm{B}_{4} \mathrm{C}\right): \mathrm{Ni}$ это отношение равно 0.151 .

C учетом этих значений максимальные полученные величины $I_{s}$, пересчитанные на массу $\mathrm{Ni}$, составляют в случае с $\mathrm{C}(\mathrm{SiC}): \mathrm{Ni}-5.6 \mathrm{emu} / \mathrm{g}$, а в случае с $\mathrm{C}\left(\mathrm{B}_{4} \mathrm{C}\right): \mathrm{Ni}-24.8 \mathrm{emu} / \mathrm{g}$, т.е. значения все же существенно меньшие, чем для свободных частиц никеля примерно тех же размеров.

\section{6. Расчет электронных состояний системы углеродных кластеров с атомами никеля}

Для выяснения причины изменения магнитных характеристик никеля в углеродном окружении была построена модель периодического кластера из 16 атомов углерода и одного атома никеля в микропоре шириной в $1 \mathrm{~nm}$ (рис. 6). Построение исходило из структуры углеродных атомов в $6 \mathrm{H}-\mathrm{SiC}$ после химического удаления кремния. В $\mathrm{SiC}$ плоскости $\mathrm{Si}$ и С чередуются. Для того, чтобы получить модельный кластер нужно взять 4 межслоевых 


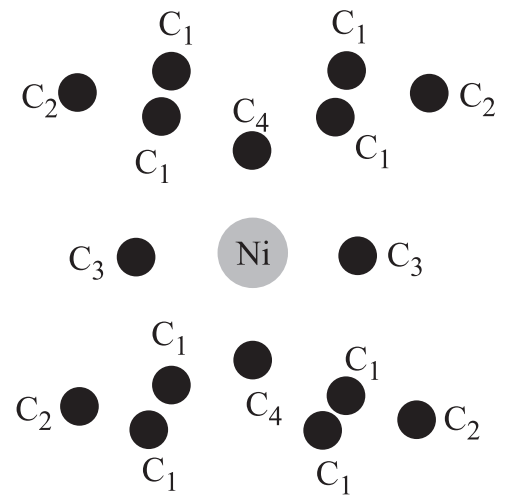

Рис. 6. Модельный кластер углерода с атомом Ni в микропоре.

пространства в карбиде кремния и удалить 2 плоскости Si. При этом, однако, между двумя графеновыми плоскостями имеется еще один углеродный слой, атомы которого должны как-то сместиться, чтобы, во-первых, решетка отрелаксировала после такого возмущения, а во-вторых, образовалась пора размером $1 \mathrm{~nm}$. Поэтому предполагалось, что пара атомов С4 (рис. 6) сместится вдоль центральной оси ближе к графеновым плоскостям с атомами C1, C2, С3. В кристаллическом графите между двумя идентичными графеновыми плоскостями располагается графеновая плоскость, смещенная вдоль радиуса гексагона так, что ее узел с тремя связями проецируется в центр соседних верхнего и нижнего гексагона. Поэтому предположение о существовании атомов типа C4 в модельном углеродном кластере является естественным. Два других атома остаются в промежуточном слое, сместившись слегка от оси С2-C2 внутрь поры. Атом металла располагается в центре поры и сильнее всего взаимодействует с атомами С3 и С4, так как они ближе всех. Атомы С1 полностью эквивалентны, а С2 отличается от С1 тем, что имеет неподалеку соседа С3. Такая модель поры была выбрана, исходя из экспериментальных фактов о наличии фрагментов углерода как с графитоподобными $s p^{2}$, так и с алмазоподобными $s p^{3}$ связями [10], и в то же время отражала бы предысторию формирования поры из структуры $\mathrm{SiC}$. Кроме того, наиболее важной характеристикой данной модели периодического кластера является наличие углеродной стенки, состоящей из двух углеродных атомных плоскостей. В работе были выполнены теоретические релятивистские расчеты методом FLAPW (полноэлектронный расчет на основе линейной комбинации присоединенных плоских волн) на ЭВМ (с программой Wien-2K) плотностей электронных состояний указанной системы периодических модельных кластеров с микропорами, получены решения для атомов $\mathrm{C}$ и $\mathrm{Ni}$.

Расчет показал, что суммарная энергия $\mathrm{C}-\mathrm{C}$ связей в кластере $(-1.257 \mathrm{Ry})$ намного ниже на шкале энергий, чем энергия всех $\mathrm{Ni}-\mathrm{C}$ связей $(-0.485 \mathrm{Ry})$. Число ближайших к атому металла связей определяется неравенством $24<N_{\mathrm{C}-\mathrm{C}}<32$ (для 3-х и 4-х координированных атомов углерода). Таким образом, энергия одной связи $\mathrm{C}-\mathrm{C}$ оказывается в диапазоне $-0.053 \mathrm{Ry}<E_{\text {bond }}(\mathrm{C}-\mathrm{C})<-0.039 \mathrm{Ry}$, тогда как энергия одной $\mathrm{Ni}-\mathrm{C}$ связи $E_{\text {bond }}(\mathrm{Ni}-\mathrm{C})=-0.04 \mathrm{Ry}$. Отсюда можно сделать вывод, что $\mathrm{C}-\mathrm{C}$ связи более предпочтительны по сравнению с $\mathrm{Ni}-\mathrm{C}$ связями. Приведенные соотношения должны определять вероятную структуру реального металлического кластера в микропоре углерода. Сравнение суммарных энергий $E(\mathrm{Ni}-\mathrm{C})$ и $E(\mathrm{Ni}-\mathrm{Ni})$, (полученных из расчетов электронной структуры чистого кристаллического металла) также подтверждает эти выводы: $\quad E(\mathrm{Ni}-\mathrm{Ni})=-0.4 \mathrm{Ry}>E(\mathrm{Ni}-\mathrm{C})=-0.485 \mathrm{Ry}$. Отсюда можно заключить, что формирование чистого кластера металлических атомов внутри поры маловероятно. Приведем для примера распределение плотности электронных состояний $\mathrm{C}_{16}$ : $\mathrm{Ni}$ в плоскости, проходящей через центр ячейки и содержащей атомы C2, C3, C4, Ni, и перпендикулярной оси $x$. Аналогичные распределения были получены и для других плоскостей. Вклады различных атомов в полную плотность электронных состояний в кластере $\mathrm{C}_{16}$ : Ni существенно различны. Имеется 8 атомов типа 1, 4 атома типа 2, и по 2 атома типов 3 и 4. Атом 5 - это один металлический атом. Были вычислены кривые плотности $p$-электронных состояний для атомов неэквивалентных позиций $p$-DOS, $s$-DOS и $d$-DOS и просуммированы.
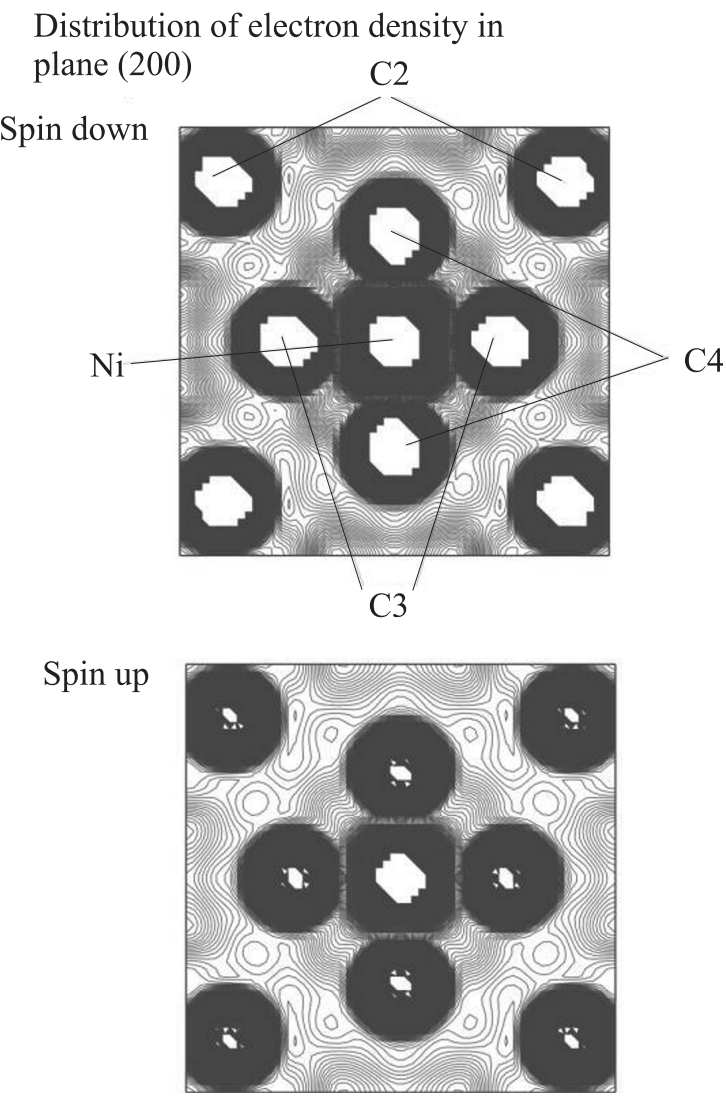

Рис. 7. Распределение электронной плотности в плоскости (200) модельного кластера $\mathrm{C}_{16}: \mathrm{Ni}$. 

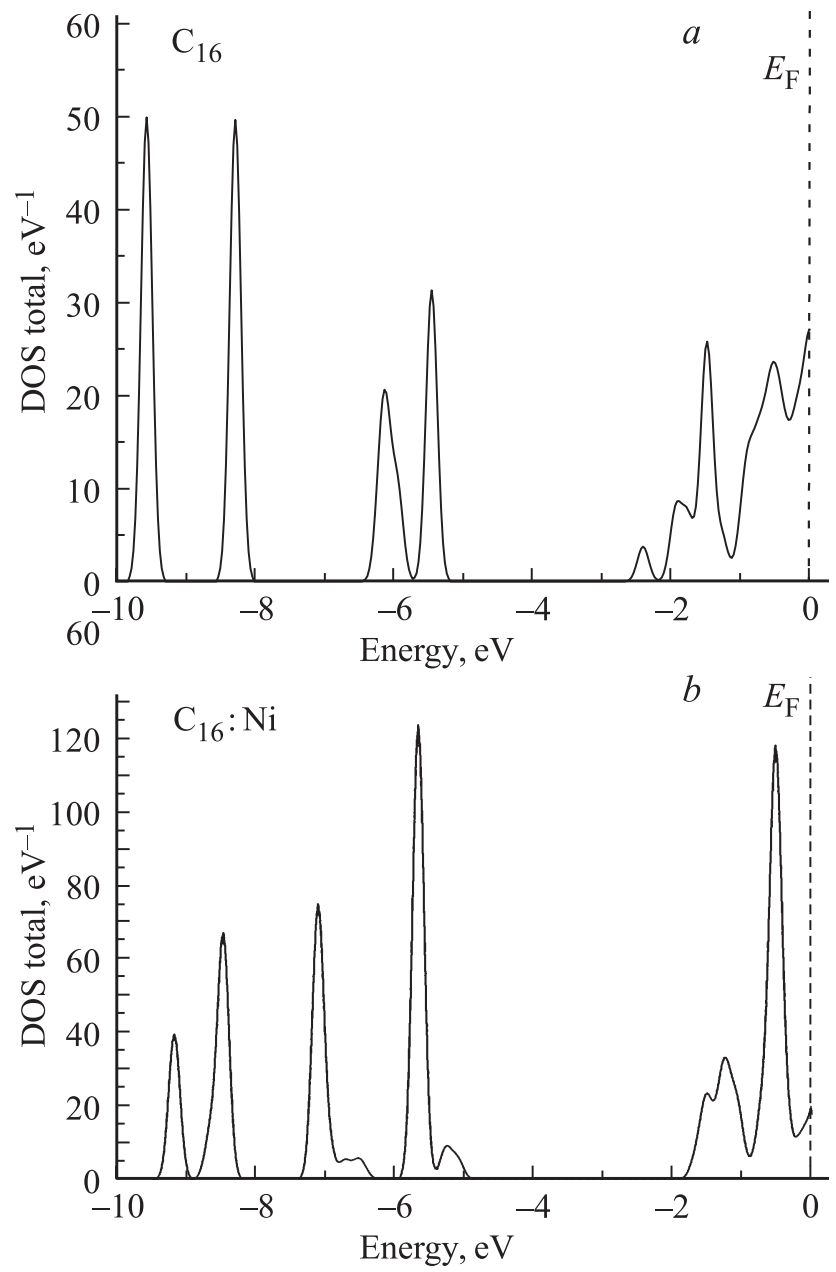

Рис. 8. Зависимости полной плотности электронных состояний (DOS) от энергии для $\mathrm{C}_{16}-(a)$ и $\mathrm{C}_{16}: \mathrm{Ni}-(b)$.

На рисунках (рис. 8) представлены кривые полной плотности электронных состояний (DOS) для кластеров $\mathrm{C}_{16}$ и $\mathrm{C}_{16}: \mathrm{Ni}$. Как видно из кривых атом $\mathrm{Ni}$ в поре уменьшает плотность состояний на уровне Ферми. Уровень Ферми показан пунктирной линией - от него отсчитываются значения энергии.

Электронные состояния, лежащие в области энергий от -5 до $-10 \mathrm{eV}$ (рис. $8, b$ ), являются $s$-состояниями атомов углерода, тогда как состояния зоны проводимости формируются р-состояниями атомов углерода, а также $s$ - и $d$-электронами атома металла. Этот результат следует из картины парциальных DOS для $s$-, $p$ - и $d$-электронных состояний. Интегрирование кривых плотности состояний (со спином вверх и спином вниз) по энергии от $-1.5 \mathrm{Ry}$ до энергии Ферми в сумме дает полное число электронов в кластере, а разность числа электронов со спином вверх и спином вниз дает магнитный момент в кластере. В результате таких вычислений магнитный момент ячейки $\mathrm{C}_{16}$ : $\mathrm{Ni}$ оказался равным $14 \mu_{B}$. Величина магнитного момента на атоме $\mathrm{Ni}: M(\mathrm{Ni})=0.13 \mu_{B}$. Наибольший магнитный момент формируется в межузельном пространстве поры, что характерно для зонного характера магнетизма. Момент на атоме никеля в углеродном кластере $\mathrm{C}_{16}$ : Ni оказался меньшим, чем для свободных атомов.

\section{7. Заключение}

Химическое введение нитрата никеля в поры порошков КНПУ с последующим отжигом образцов в водороде приводит к образованию наноразмерных металлических никелевых кластеров в углеродном окружении. Образцы, полученные таким способом, обладают слабыми магнитными свойствами. Намагниченность насыщения, приведенная к массе Ni в образцах, оказывается существенно меньшей, чем для свободных частиц металлического никеля примерно тех же размеров, что и кластеры никеля в КНПУ, что подтверждает имеющиеся литературные экспериментальные данные об уменьшении намагниченности частиц Ni в углеродном окружении.

Для объяснения полученных в работе результатов выполнен компъютерный расчет электронных свойств периодического углеродного кластера $\mathrm{C}_{16}$ : $\mathrm{Ni}$ с атомом $\mathrm{Ni}$ в нанопоре и вычислен магнитный момент кластера и магнитный момент атома $\mathrm{Ni}$.

Последняя величина оказалась значительно меньшей, чем для свободных атомов Ni. Отсюда можно сделать вывод, что наблюдаемое в экспериментах уменьшение намагниченности никелевых кластеров в углеродном окружении связано с адсорбционным взаимодействием электронных подсистем никеля и углерода.

\section{Список литературы}

[1] В.А. Федосюк, А.М. Данишевский, Д.А. Курдюков, В.Б. Шуман, С.Г. Гордеев. ФТТ 45, 1667 (2003).

[2] K.H. Ang, I. Alexandrou, N.D. Mathur, G.A.J. Amaratunga, S. Haq. Nanjtechnology 15, 520 (2004).

[3] P.B. Oliete, T.C. Rojas, A. Fernandez, A. Gedanken, Y. Koltupin, F. Palacio. Acta Mater. 52, 2165, (2004).

[4] C.N. He, X.W. Du, J. Ding, C.S. Shi, J.J. Li, N.Q. Zhao, L. Cui. Carbon 44, 2330 (2006).

[5] P. Boria, M. Sevilla, J.A. Blanko, A.B. Fuertes. Carbon 44, 1954 (2006).

[6] В.А. Цурин, А.Е. Ермаков, М.А. Уймин, А.А. Мысин, Н.Н. Щеголева. ФТТ 56, 287 (2014).

[7] C.D. Graham Jr. J. Appl. Phys. 53, 2033 (1982).

[8] T.B. Massalsky. Binary Alloy Phase Diagrams. American Soc. For Metals, Metals Park, Ohio. (1986). p. 715.

[9] G. Laudisio, R.K. Dash, J.P. Singer, G. Yushin, Y. Gogotsi, J.E. Fischer. Langmuir 22, 8945 (2006).

[10] E. Smorgonskaya, R. Kyutt, A. Danishevskii, C. Jardin, R. Meaudre, O. Marty, S. Gordeev, A. Grechinskaya. J. NonCrystal. Solids 299-302, 810 (2002).

[11] J. Frenkel, J. Dorfman. Nature 126, 274(1930).

[12] П.А. Чернавский. Рос. хим. журн. 46, 19 (2002).

[13] О.А. Иванов, А.Е. Ермаков, Я.С. Шур. ФММ 33, 752 (1972). 